\title{
Management and results of treatment of breast cancer patients having sentinel lymph node micrometastases
}

\author{
T. NOWIKIEWICZ ${ }^{1, *}$, E. SRUTEK ${ }^{2}$, M. JANKOWSKI², M. LAS-JANKOWSKA ${ }^{3}$, M. KLAG ${ }^{2}$, D. KOZAK², I. GLOWACKA², W. ZEGARSKI ${ }^{2}$ \\ ${ }^{1}$ Department of Clinical Breast Cancer and Reconstructive Surgery, Oncology Center, Prof Lukaszczyk Memorial Hospital, Bydgoszcz, Poland; \\ ${ }^{2}$ Surgical Oncology Clinic Collegium Medicum Nicolaus Copernicus University, Oncology Center, Prof Lukaszczyk Memorial Hospital, Bydgoszcz, \\ Poland; ${ }^{3}$ Department of Clinical Oncology, Oncology Center, Prof Lukaszczyk Memorial Hospital, Bydgoszcz, Poland
}

*Correspondence: tomasz.nowikiewicz@gmail.com

Received February 18, 2013 / Accepted September 4, 2013

\begin{abstract}
According to current therapeutic guidelines, finding micrometastases in the sentinel node (SLN) of a patient with non-advanced breast cancer is not an absolute indication for adjuvant axillary lymph node dissection (ALND). This work presents our experiences regarding this clinical problem. 1071 breast cancer patients were referred for sentinel node biopsy between January 2004 and December 2011. Metastases were found in 245 of the removed lymph nodes. In 49 patients lymph node changes turned out to be micrometastases or isolated tumor cells (ITC). ALND was performed in 38 cases of sentinel node micrometastases or ICTs. In three patients involvement of other axillary lymph nodes was found in the studied tissue material ( $7.9 \%$ vs. $37.9 \%$ for metastases $>2 \mathrm{~mm}$ ). The remaining patients with micrometastases in the SLN (11/49) were treated conservatively. No local axillary recurrences or neoplastic metastases were found in this group of patients with SLN micrometastases. Mean follow-up period in patients who had undergone ALND was 18.0 months (4 to 60 months) and 21.4 months (9-40 months) in patients without ALND. Non-radical surgical treatment in the presence of SLN micrometastases in patients with non-advanced breast cancer does not lead to therapeutic failure (local axillary recurrences, distant metastases). Obtaining favorable outcomes of conservative treatment in the analyzed group of patients does not require additional modification of the adjuvant therapy.
\end{abstract}

Key words: breast cancer, sentinel lymph node biopsy, micrometastases, treatment and results

The state of axillary lymph nodes in breast cancer patients is a decisive clinical factor influencing long-term outcome [1]. According to the current classification provided by the American Joint Committee on Cancer (AJCC), we distinguish the following among lymph node metastases depending on size: isolated tumor cells (ITC) - lesions up to $0.2 \mathrm{~mm}$ in diameter, micrometastases (greater than $0.2 \mathrm{~mm}$ in size but not exceeding $2 \mathrm{~mm}$ ) and metastases (lesions exceeding $2 \mathrm{~mm}$ ) [2].

Identification of metastases in histopathological examination of one excised sentinel lymph node may be an indication for continuing surgical treatment in breast cancer patients $[3,4]$. That usually concerns the largest lesions listed by the AJCC. Also, according to the recommendations of a panel of experts at the XII Conference in St Gallen (March 2011), identification of micrometastases or ITC in a single SLN does not require performing adjuvant axillary lymph node dissection [3].
This work presents our experiences gathered to date on clinical problems related to therapy of patients with non-advanced breast cancer and SLN metastases or ITC.

\section{Materials and methods}

Between January 2004 and December 2011 in the Department of Breast Neoplasms and Reconstruction Surgery and the Department and Clinic of Oncological Surgery of the Bydgoszcz Oncology Center (Nicolaus Copernicus University Collegium Medicum) 1071 breast cancer patients were referred for sentinel lymph node biopsy (SLNB). None of the treated patients initially exhibited suspicious clinical signs in the area of axillary lymph nodes (cN0 patients). Mean patient age was $56.4 \pm 9.4$ years (patients aged 23 to 83 years).

In 1012 cases $(94.5 \%)$ the node in question was identified as a result of SLNB. Lymph nodes excised during SLNB 
were subjected to immediate histopathological assessment or examined in a normal time mode (operating surgeon made the decision with regard to the manner of histopathological examination of the excised SLN). Intraoperative examination consisted of microscopic assessment of frozen tissue sections stained with hematoxylin and eosin (HE staining). Paraffin block sections were used for final pathological evaluation of the SLN (or for histopathological examination in a regular mode of examination).

If no metastatic lesions had been noted during evaluation of routinely HE stained paraffin sections, additional immunohistochemical (IHC) tests were performed in some patients. The decision whether to perform such test was up to the examining histopathologist. Presence of broad-spectrum AE1/AE3 and anti-CK AE1/AE3 cytokeratins (test was performed using the En-Vision method with monoclonal anti-CK7 and antiCK AE1/AE3 by Dako company) was determined during the study.

Failure to identify the sentinel lymph node during the SLNB (in 59 patients) necessitated simultaneous axillary lymph node dissection (ALND).

In $22.9 \%$ of all subjects referred for SLNB (245/1071) histopathological examination of sections revealed the presence of metastases in the excised lymph nodes. Diagnosed lymph node lesions were categorized according to the AJCC classification [2].

Lesions identified in the majority of metastatically changed lymph nodes exceeded $2 \mathrm{~mm}$ (in 174 subjects after SLN excision and in 22 cases of ALND performed due to failure to identify SLN). Following the diagnosis, all patients after SLNB were subjected to adjuvant axillary lymph node dissection - immediate (if the intraoperative assessment of SLN was positive) or delayed (if SLN metastases were identified in final histopathological examination).
In 48 patients lymph node changes were identified as micrometastases - pN1mi (in 47 patients they involved the excised SLN and in 1 case after ALND due to failure to visualize SLN). SLN infiltration by ITC (pNO(i+) - detailed data are presented in Figure 1) was found in one patient. Decision to proceed with more radical surgical treatment was made by the patient after being provided with detailed information regarding possible future therapeutic options. Recommendations on indications for adjuvant treatment (chemo-, radio-, immuno-, and hormonotherapy) came from generally accepted standards of breast cancer treatment $[3,5,6]$.

All patients after SLNB were followed up with clinical examination and ultrasound scan of the spared axillary lymph nodes (at 3-6-month intervals). Breast and axillary ultrasound examinations were performed every 12 months in patients after adjuvant ALND.

A chi-square test was used for statistical analysis (comparison of two samples with normal distributions). Calculations were performed with SAS software. Statistical difference between compared groups of data was noted when p-value was below 0.05 .

Diagnostic value of intraoperative examination of excised SLNs was also analyzed, determining the sensitivity (proportion of true positive to the sum of true positive and false negative results) and specificity (proportion of true negative to the sum of true negative and false positive results).

\section{Results}

Mean age of the patients referred for SLNB was $56.4 \pm 9.4$ years. Age of patients with SLN changes was insignificantly lower: $54.6 \pm 9.2$ years $(56.4 \pm 8.4$ years for patients with micrometastases or ITC and $54.1 \pm 9.4$ years in patients with metastases larger than $2 \mathrm{~mm} ; \mathrm{p}<0.01)$. Detailed data analysis

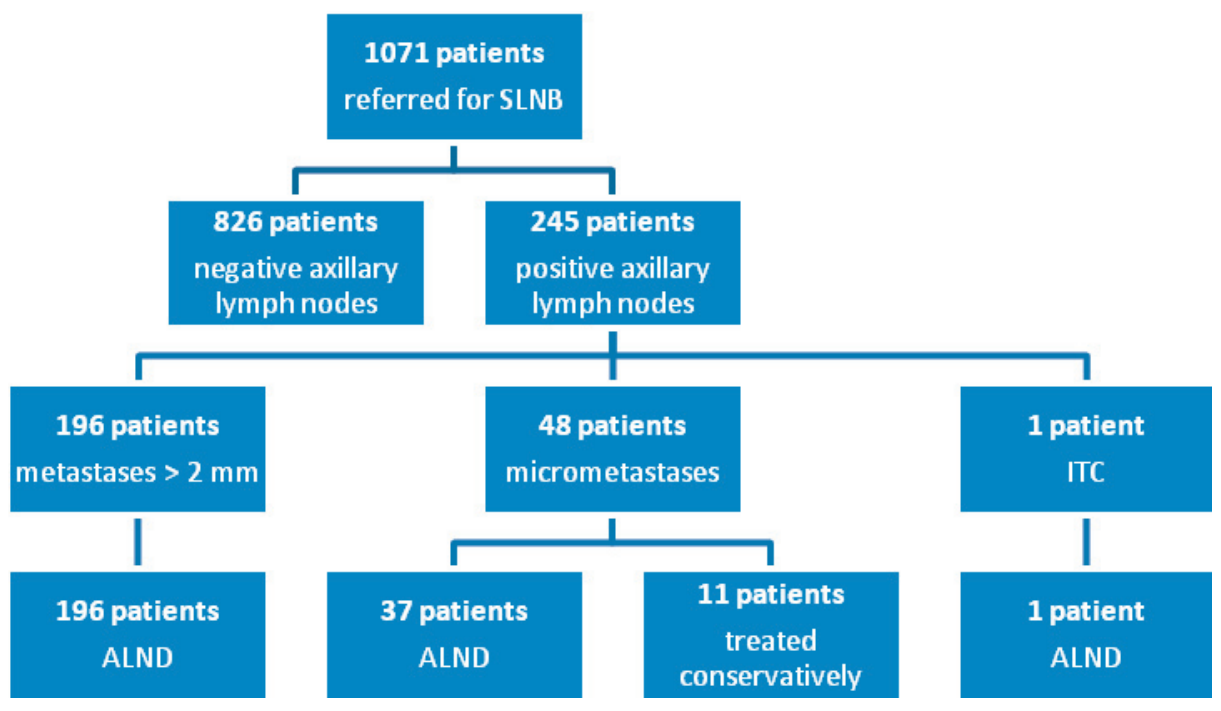

Figure 1. Patients referred for SLNB - metastatic lesions identified in axillary lymph nodes and type of adjuvant treatment for radical SLN resection. 
regarding node positive patients may be found in Table 1 below.

A completion ALND was performed in 37 cases of SLN micrometastases or ITC in accordance with patients' decisions. Histopathological examination revealed involvement of other lymph nodes - non-sentinel lymph nodes, in three patients (7.9\%). In two patients metastases were found in lymph nodes of the floor of axillary fossa, while in one patient - involvement of central axillary lymph nodes was noted (infiltration of the capsules of the involved lymph nodes was seen in two cases). In the presence of SLN metastases larger than $2 \mathrm{~mm}$ mentioned situation involved $37.9 \%$ of all patients - the difference was statistically significant $(\mathrm{p}=0.0004)$ - Table 1 .

The remaining patients with SLN micrometastases (11/48) were treated conservatively.

Excised SLNs were usually examined by immediate verification of histopathological sections - this approach was used in $88.9 \%$ of patients undergoing SLNB. The majority of micrometastases were diagnosed by immunohistochemical studies $(61.7 \%$ vs. $8.6 \%$ for metastases $>2 \mathrm{~mm})$. They also facilitated identification of ITC in one case. Detailed data regarding the diagnostics of identified SLN metastases are presented in Table 2.

Sensitivity of intraoperative histopathological SLN examination was $62.5 \%$. It reached $7.5 \%$ for micrometastases and $77.5 \%$

Table 1. Node positive patients referred for SLNB.

\begin{tabular}{|c|c|c|c|}
\hline & $\begin{array}{c}\text { Micrometastases } \\
\text { and ITC } \\
\mathrm{n}=49(\%)\end{array}$ & $\begin{array}{c}\text { Metastases }>2 \mathrm{~mm} \\
\mathrm{n}=196(\%)\end{array}$ & $\mathrm{p}$ \\
\hline Age - mean (years) & $56.4 \pm 8.4$ & $54.1 \pm 9.4$ & ns \\
\hline cT1 & $35(71.4 \%)$ & $106(54.1 \%)$ & $\mathrm{p}<0,05$ \\
\hline cT2 & $14(28.6 \%)$ & $88(44.9 \%)$ & $\mathrm{p}<0,05$ \\
\hline cT3 & $0(0.0 \%)$ & $2(1.0 \%)$ & ns \\
\hline nonpalpable tumor & $16(32.7 \%)$ & $43(21.9 \%)$ & ns \\
\hline $\mathrm{DC}$ & $41(83.7 \%)$ & $167(85.2 \%)$ & ns \\
\hline LC & $6(12.2 \%)$ & $17(8.7 \%)$ & ns \\
\hline others & $2(4.1 \%)$ & $12(6.1 \%)$ & ns \\
\hline $\mathrm{pT} 1$ & $35(71.4 \%)$ & $112(57.1 \%)$ & $\mathrm{p}<0,05$ \\
\hline pT2 & $12(24.5 \%)$ & $80(40.8 \%)$ & $\mathrm{p}<0,05$ \\
\hline pT3 & $0(0.0 \%)$ & $2(1.0 \%)$ & ns \\
\hline nd & $2(4.1 \%)$ & $2(1.0 \%)$ & ns \\
\hline G1 & $8(16.3 \%)$ & $15(7.6 \%)$ & $\mathrm{p}<0,05$ \\
\hline $\mathrm{G} 2$ & $30(61.2 \%)$ & $126(64.3 \%)$ & ns \\
\hline G3 & $8(16.3 \%)$ & $49(25.0 \%)$ & ns \\
\hline nd & $3(6.1 \%)$ & $6(3.1 \%)$ & ns \\
\hline ER positive & $43(87.8 \%)$ & $166(84.7 \%)$ & ns \\
\hline HER2 positive & $4(8.2 \%)$ & $25(12.8 \%)$ & ns \\
\hline ALND & $37(77.1 \%)$ & $196(100.0 \%)$ & ns \\
\hline $\begin{array}{l}\text { nSLN metastases } \\
\text { (patients after SLNB) }\end{array}$ & $3(7.9 \%)$ & $66(37.9 \%)$ & $\mathrm{p}<0,05$ \\
\hline \multicolumn{4}{|c|}{$\begin{array}{l}\text { T - clinical (c) / pathological (p) size of primary tumour, nd - no data, DC } \\
\text { - ductal invasive carcinoma, LC - lobular invasive carcinoma, G - assess- } \\
\text { ment of malignance degree (graiding), HER2 - status of overexpresion / } \\
\text { amplification of HER2, ER - status of estrogen receptors, ALND - axillary } \\
\text { lymphadenectomy, nSLN - non sentinel lymph nodes }\end{array}$} \\
\hline
\end{tabular}

Table 2. Types of metastatic lesions identified in SLNs.

\begin{tabular}{lccc}
\hline $\begin{array}{l}\text { Histopathological } \\
\text { examination }\end{array}$ & $\begin{array}{c}\text { Micrometastases } \\
\text { and ITC } \\
{[\mathrm{n}]}\end{array}$ & $\begin{array}{c}\text { Metastases } \\
>2 \mathrm{~mm} \\
{[\mathrm{n}]}\end{array}$ & $\mathrm{p}$ \\
\hline Intraoperative examination & $3(6.3 \%)$ & $118(67.8 \%)$ & $\mathrm{p}<0,05$ \\
Final examination (HE) & $15(31.3 \%)$ & $41(23.6 \%)$ & $\mathrm{ns}$ \\
Final examination (IHC) & $30(62.5 \%)$ & $15(8.6 \%)$ & $\mathrm{p}<0,05$ \\
TOTAL & $48(100 \%)$ & $174(100 \%)$ & \\
\hline
\end{tabular}

$\mathrm{n}$ - number of patients; ITC - isolated tumor cells; HE - hematoxylin-eosin staining; IHC - immunohistochemical examination;

for macrometastases. Specificity of this method was $100 \%$ for both types of metastases. Thereby, the proportion of false negative results was $92.5 \%$ (37/40) for micrometastases and $22.5 \%$ (34/151) for macrometastases for intraoperative SLN examination. At the same time, there were no false positive results of immediate SLN examinations for the presence of metastases.

None of the patients with diagnosis of SLN micrometastases on the basis of intraoperative frozen section examinations was found to have non-SLN metastases following ALND. However, all cases of metastatic lesions (in the form of micrometastases or ITC) in SLN or other lymph nodes of the axillary fossa concerned patients with false negative results of intraoperative examination.

In the studied clinical material, there were 5 patients with SLN metastases, in whom radical surgical ALND was not performed and who were referred for adjuvant chemotherapy (CHTH) and 15 patients after axillary lymph node dissection (Table 3). All patients received systemic therapy with anthracyclines - AC/EC or FEC schemes were chosen depending on clinical situations. In all cases, $\mathrm{CHTH}$ administration ensued from general indications, not only from the presence of SLN micrometastases in the group of patients without ALND qualified for conservative treatment.

No recurrences or neoplastic dissemination were observed in the group of patients with SLN micrometastases or ITC involvement regardless of the type of adjuvant treatment. Mean postoperative follow-up time for patients with SLN micrometastases or ITC after adjuvant ALND was 18.0 months (from 4 to 60 months), while in the $\mathrm{pN} 1 \mathrm{mi}$ group without reoperation it was 21.4 months (9-40 months).

On the other hand, therapeutic failures were observed in 9 subjects out of the remaining patients referred for SLNB

Table 3. Administration of adjuvant therapy in a group of patients $\mathrm{pN} 1 \mathrm{mi}$ and $\mathrm{pNO}(\mathrm{i}+)$.

\begin{tabular}{lccc}
\hline $\begin{array}{l}\text { Histopathological } \\
\text { examination }\end{array}$ & $\begin{array}{c}\text { Patients after } \\
\text { ALND } \\
{[\mathrm{n}=38]}\end{array}$ & $\begin{array}{c}\text { Patients without } \\
\text { ALND } \\
{[\mathrm{n}=11]}\end{array}$ & $\mathrm{p}$ \\
\hline Adjuvant CHTH & $15(39.5 \%)$ & $5(45.5 \%)$ & $\mathrm{ns}$ \\
Patients in follow-up & $38(100 \%)$ & $11(100 \%)$ & \\
\hline
\end{tabular}


Table 4. Therapeutic failures observed in patients referred for SLNB.

\begin{tabular}{|c|c|c|c|}
\hline Type of recurrence & $\begin{array}{l}\text { pN0 patients } \\
{[\mathrm{n}=826]}\end{array}$ & $\begin{array}{l}\text { pN1 patients } \\
{[\mathrm{n}=196]}\end{array}$ & $\begin{array}{c}\text { pN1mi and } \\
\text { pN0(i+) patients } \\
{[\mathrm{n}=49]}\end{array}$ \\
\hline $\begin{array}{l}\text { Local recurrence } \\
\text { (breast, mastectomy scar) }\end{array}$ & $5(0.61 \%)$ & 0 & 0 \\
\hline Axillary fossa recurrence & $1(0.12 \%)$ & 0 & 0 \\
\hline Distant metastases & $1(0.12 \%)$ & $1(0.51 \%)$ & 0 \\
\hline $\begin{array}{l}\text { Local recurrence } \\
+ \text { distal metastases }\end{array}$ & $1(0.12 \%)$ & 0 & 0 \\
\hline TOTAL & $8(0.97 \%)$ & $1(0.51 \%)$ & 0 \\
\hline
\end{tabular}

(patients with SLN metastases $>2 \mathrm{~mm}-\mathrm{pN} 1$ and patients without lymph node changes - pN0) - mainly in the form of local recurrences (Table 4 contains detailed data).

\section{Discussion}

In the analyzed group of patients, micrometastases or ICT were identified in 49 subjects ( $20 \%$ of all lymph node metastases). In 37 cases adjuvant axillary lymph node dissection was performed after the diagnosis. As a result, metastases were identified in other lymph nodes in three patients. The remaining patients with SLN micrometastases were treated conservatively. Postoperative follow-up did not reveal recurrences or neoplastic dissemination in this group of patients. According to the panel of experts from St Gallen, due to the lack of statistically significant differences regarding the overall survival (OS) as well as recurrence-free survival (RFS), there is no need for performing ALND in breast cancer patients after discovering micrometastases or ITC in sentinel lymph nodes [3]. The authors also do not recommend radicalization of surgical treatment in patients with SLN changes diagnosed using IHC methods. They also approve conservative treatment in patients with involvement of two lymph nodes removed during SLNB (it concerns N0 patients in the postoperative assessment subjected to breast-sparing treatment regardless of the size of SLN metastasis).

Patients included in the randomized ACOSOG Z0011 study fulfilled the conditions mentioned above [4]. It involved 891 patients with invasive breast cancer (cT1-2) treated with surgery in the period 1999-2004 (primary tumor excision and SLNB), in whom histopathological evaluation revealed SLN infiltration by metastatic lesions (regardless of their size, lesions were assessed in HE staining). Some patients (420) were referred for adjuvant ALND, while SLNB alone was performed in 436 cases.

Compared groups did not differ significantly with regard to age, size or histological type of the tumor, steroid receptor status, presence of vascular invasion and grade of histological malignancy. No statistical significance was noted with regard to 5 -year survival (91.8\% of patients after ALND vs. $92.5 \%$ - SLNB only) and RFS ( $82.2 \%$ and $83.9 \%$ respectively). Moreo- ver, proportions of use of adjuvant therapy were similar in both groups (96.0\% - ALND, 97.0\% - SLNB).

We corroborated the above observations in the analyzed clinical material. In comparison to $\mathrm{pN} 0$ and $\mathrm{pN} 1$ patients, there were no statistically significant differences with regard to therapeutic failure in the group with SLN ITC or micrometastasis. Conclusive determination of long-term results of oncological treatment will be possible after a longer follow-up period (most patients underwent SLNB in the last two years of the study).

Observations made by Giuliano et al. [4] are corroborated by those of Pugliese et al. [7]. There were no significant differences in the OS or RFS when comparing patients with metastatic SLN lesions diagnosed by immunohistochemistry - pNo(i+) with patients without metastases in the lymph nodes excised during SLNB ( $\mathrm{pN} 0$ ). However, as opposed to the ACOSOG Z0011 study, administration of adjuvant $\mathrm{CHTH}$ differed significantly between the analyzed groups $-75 \%$ in pN0(i+) vs. $43 \%$ - pN0 ( $<<0.001)$. Authors also demonstrated that in the $\mathrm{pN} 0(\mathrm{i}+)$ group with metastases in the consecutive, non-sentinel axillary lymph nodes the proportion of disease recurrences was significantly higher compared to patients without SLN metastases (20\% vs. $4.8 \%$ ).

The last observation made by Pugliese et al. [7] indicates a problem of selecting patients with involvement of sentinel lymph node- $\mathrm{pN} 1 \mathrm{mi}$ and $\mathrm{pN}(\mathrm{i}+)$, as well as consecutive axillary lymph nodes. Worse long-term treatment outcome may be expected in the mentioned case, which is why it is necessary to find an answer to the following questions: how to predict the presence of lymph node changes outside of SLN and what could be the alternative to adjuvant ALND?

Use of nomograms offers partial solution to this problem of assessing the probability of non-sentinel lymph node metastases. Originators of such solutions underscore their proven clinical value [8-11]. D'Eredita et al. [12] and other authors [13-15] confirm it as well.

According to Giuliano et al. conservative treatment of patients with SLN metastases, including micrometastases, is associated with the necessity of administering adjuvant $\mathrm{CHTH}$ therapy in a large percentage of patients (as much as $97 \%$ of patients) [4]. Analyses conducted by other authors corroborate that $[3,7,16,17]$.

In our clinical material administration of adjuvant $\mathrm{CHTH}$ therapy in a group of $\mathrm{pN} 1 \mathrm{mi}$ and $\mathrm{pN} 0(\mathrm{i}+)$ patients was less common (it involved $40.8 \%$ of such patients - 20/49), but facilitated positive treatment outcomes. Simultaneously, adjuvant hormonotherapy was administered in each case (expression of steroid ER receptors was identified in the cells of primary tumors of all patients from this subgroup). Continuation of clinical observations as well as analysis conducted on a larger group of patients is necessary for better assessment.

On the other hand, multicenter AMAROS clinical study (After Mapping of the Axilla: Radiotherapy Or Surgery) demonstrated the possibility of effectively replacing adjuvant axillary lymph node dissection with axillary fossa radiotherapy 
$[18,19]$. No cases of axillary recurrence were observed in the group of patients subjected to radiotherapy. The percentage of axillary lymph node recurrences in patients after ALND performed after SLNB with positive SLN histopathology amounted to $1.2 \%$.

Giobuin et al. [16] point to the occurrence of non-sentinel lymph node metastatic lesions in patients with SLN micrometastases or ITC. Among 1076 patients undergoing SLNB, lymph node changes identified only with IHC were diagnosed in 49 subjects. An adjuvant ALND performed in 31 cases revealed metastases in axillary lymph nodes other than SLN in as much as $23 \%$ of patients. Comparison of pNo(i+) patients with the $\mathrm{pN} 0$ (sn) group did not show significant differences with regard to OS and RFS. However, in any case of sentinel lymph node involvement (including the $\mathrm{pNO}(\mathrm{i}+$ ) group) patients received adjuvant $\mathrm{CHTH}$.

Reed et al. [20] and Tan et al. [21] also noted the possibility of obtaining better long-term treatment outcomes in a group of pN0(i+) patients compared with pN1 patients. Carvalho et al. observed on the other hand, that involvement of other lymph nodes should be expected only in case of SLN micrometastases diagnosed in a routine histopathological examination (HE staining) [17]. In the studied group such situation concerned $24 \%$ of patients. At the same time, no non-sentinel lymph node metastases were seen in $\mathrm{pNO}(\mathrm{i}+)$ patients [17].

In the analyzed clinical material, identifying micrometastasis during an intraoperative histopathological SLN examination did not increase the frequency of diagnosis of metastatic lesions in lymph nodes excised during adjuvant ALND. Therefore, in our opinion it does not have to constitute an indication for increasing the extent of surgery.

\section{Conclusions}

Not radicalizing surgical treatment in case of SLN micrometastases in patients with non-advanced breast cancer does not lead to failure of therapeutic outcomes (axillary recurrences, distant metastases). However, taking into account the appearance of new results of studies on the role of micrometastases and ITC in the discussed clinical situation, each case should be treated individually and even performing adjuvant axillary lymphadenectomy should be considered. Obtaining favorable outcomes of conservative treatment in the analyzed group of patients does not require additional modification of adjuvant therapy.

\section{References}

[1] DONEGAN WL. Tumor-related prognostic factors for breast cancer. CA Cancer Clin J 1997; 47: 28-51. http://dx.doi. org/10.3322/canjclin.47.1.28

[2] GREENE FL, American Joint Committee on Cancer, American Cancer Society, AJCC. Cancer Staging Manual, 6th ed. New York: Springer-Verlag; 2002. http://dx.doi.org/10.1007/9781-4757-3656-4
[3] GOLDHIRSCH A, WOOD WC, COATES AS, GELBER RD, THURLIMANN B and panel members: Strategies for subtypes-dealing with the diversity of breast cancer: highlights of the St Gallen International Expert Consensus on the Primary Therapy of Early Breast Cancer 2011. Ann Oncol. 2011; 22: 1736-47. http://dx.doi.org/10.1093/annonc/mdr304

[4] GIULIANO AE, HUNT KK, BALLMAN KV, BEITSCH PD, WHITWORTH PW et al. Axillary dissection vs no axillary dissection in women with invasive breast cancer and sentinel node metastasis. A randomized clinical trial. JAMA 2011; 305: 569-75. http://dx.doi.org/10.1001/jama.2011.90

[5] GOLDHIRSCH A, INGLE JN, GELBER RD, COATES AS, THURLIMANN B and panel members: Thresholds for therapies: highlights of the St Gallen International Expert Consensus on the Primary Therapy of Early Breast Cancer 2009. Ann Oncol 2009; 20: 1319-1329. http://dx.doi.org/10.1093/ annonc/mdp322

[6] GOLDHIRSCH A, WOOD WC, GELBER RD, COATES AS, THURLIMANN B and panel members: Progress and promise: highlights of the international expert consensus on the primary therapy of early breast cancer 2007. Ann Oncol 2007; 18: 1133-1144. http://dx.doi.org/10.1093/annonc/mdm271

[7] PUGLIESE M, STEMPEL M, PATIL S, HSU M, HO A et al. The clinical impact and outcomes of immunohistochemistryonly metastasis in breast cancer. Am J Surg. 2010; 200: 368-73. http://dx.doi.org/10.1016/j.amjsurg.2009.10.016

[8] VANZEE KJ, MANASSEH DM, BEVILACQUA JL, BOOLBOL SK, FEY JV et al. A nomogram for predicting the likelihood of additional nodal metastases in breast cancer patients with a positive sentinel node biopsy. Ann Surg Oncol. 2003; 10: 1140-51. http://dx.doi.org/10.1245/ASO.2003.03.015

[9] BARRANGER E, COUTANT C, FLAHAULT A, DELPECH Y, DARAI E et al. An axilla scoring system to predict nonsentinel lymph node status in breast cancer patients with sentinel lymph node involvement. Breast Cancer Res Treat. 2005; 91: 113-119. http://dx.doi.org/10.1007/s10549-0045781-Z

[10] PAL A, PROVENZANO E, DUFFY SW, PINDER SE, PURUSHOTHAM AD. A model for predicting non-sentinel lymph node metastatic disease when the sentinel lymph node is positive. Br J Surg 2008; 95: 302-309. http://dx.doi. org $/ 10.1002 /$ bjs. 5943

[11] KOHRT HE, OLSHEN RA, BERMAS HR, GOODSON WH, WOOD DJ et al. New models and online calculator for predicting non-sentinel lymph node status in sentinel lymph node positive breast cancer patients. BMC Cancer 2008; 8: 66 . http://dx.doi.org/10.1186/1471-2407-8-66

[12] D'EREDITA G, TROILO VL, GIARDINA C, NAPOLI A, RUBINI $G$ et al. Sentinel lymph node micrometastasis and risk of non-sentinel lymph node metastasis: validation of two breast cancer nomograms. Clinical Breast Cancer 2010; 10: 445-51. http://dx.doi.org/10.3816/CBC.2010.n.058

[13] GUR AS, UNAL B, OZBEK U, OZMEN V, AYDOGAN F et al. Validation of breast cancer nomograms for predicting the non-sentinel lymph node metastases after a postive sentinel lymph node biopsy in a multi-center study. Eur J Surg Oncol 2010; 36: 30-5. http://dx.doi.org/10.1016/j.ejso.2009.05.007 
[14.] VAN LA PARRA RFD, ERNST MF, BEVILACQUA JLB, MOL SJJ, VAN ZEE KJ et al. Validation of a nomogram to predict the risk of nonsentinel lymph node metastases in breast cancer patients with a positive sentinel node biopsy: validation of the MSKCC breast nomogram. Ann Surg Oncol 2009; 16: 1128-1135. http://dx.doi.org/10.1245/s10434-009-0359-y

[15] DAUPHINE CE, HAUKOOS JS, VARGAS MP, ISAAC NM, KHALKALI I et al. Evaluation of three scoring systems predicting non sentinel node metastasis in breast cancer patients with a positive sentinel node biopsy. Ann Surg Oncol 2007; 14: 1014-9. http://dx.doi.org/10.1245/s10434-006-9223-5

[16] GIOBUIN SM, KAVANAGH DO, MYERS E, DOHERTY AO, QUINN CM et al. The significance of immunohistochemistry positivity in sentinel nodes which are negative on haematoxylin and eosin in breast cancer. Eur J Surg Oncol. 2009; 35: 1257-60. http://dx.doi.org/10.1016/j.ejso.2009.04.004

[17] CARVALHO MJ, DIAS MF, SILVA TS, CUSTODIO S, DE OLIVEIRA CF. Breast cancer patients with micrometastases in sentinel lymph nodes: differences considering additional metastatic lymph nodes. Eur J Gynaecol Oncol. 2009; 30: 631-4.
[18] RUTGERS EJ, MEIJNEN P, BONNEFOI H. Clinical trials update of the European Organization for Research and Treatment of Cancer Breast Cancer Group. Breast Cancer Res. 2004; 6: 165-9. http://dx.doi.org/10.1186/bcr906

[19] STRAVER ME, MEIJNEN P, VAN TIENHOVEN G, VAN DE VELDE CJ, MANSEL RE et al. Sentinel node identification rate and nodal involvement in the EORTC 10981-22023 AMAROS trial. Ann Surg Oncol. 2010 Jul; 17: 1854-61. http://dx.doi. org/10.1245/s10434-010-0945-Z

[20] REED J, ROSMAN M, VERBANAC KM, MANNIE A, CHENG $\mathrm{Z}$ et al. Prognostic implications of isolated tumor cells and micrometastases in sentinel lymph nodes of patients with invasive breast cancer: 10-year analysis of patients enrolled in the prospective East Carolina University/Anne Arundel Medical Center sentinel node multicenter study. J Am Coll Surg. 2009; 208: 333-40. http://dx.doi.org/10.1016/j.jamcollsurg.2008.10.036

[21] TAN LK, GIRI D, HUMMER AJ, PANAGEAS KS, BROGI E et al. Occult axillary node metastases in breast cancer are prognostically significant: results in 368 node-negative patients with 20-year follow-up. J Clin Oncol. 2008; 26: 1803-9. http://dx.doi.org/10.1200/JCO.2007.12.6425 